\title{
REVIEW
}

\section{Vehicle accidents related to sleep: a review}

\author{
Jim Horne, Louise Reyner
}

\begin{abstract}
Falling asleep while driving accounts for a considerable proportion of vehicle accidents under monotonous driving conditions. Many of these accidents are related to work-for example, drivers of lorries, goods vehicles, and company cars. Time of day (circadian) effects are profound, with sleepiness being particularly evident during night shift work, and driving home afterwards. Circadian factors are as important in determining driver sleepiness as is the duration of the drive, but only duration of the drive is built into legislation protecting professional drivers. Older drivers are also vulnerable to sleepiness in the mid-afternoon. Possible pathological causes of driver sleepiness are discussed, but there is little evidence that this factor contributes greatly to the accident statistics. Sleep does not occur spontaneously without warning. Drivers falling asleep are unlikely to recollect having done so, but will be aware of the precursory state of increasing sleepiness; probably reaching a state of fighting off sleep before an accident. Self awareness of sleepiness is a better method for alerting the driver than automatic sleepiness detectors in the vehicle. None of these have been proved to be reliable and most have shortcomings. Putative counter measures to sleepiness, adopted during continued driving (cold air, use of car radio) are only effective for a short time. The only safe counter measure to driver sleepiness, particularly when the driver reaches the stage of fighting sleep, is to stop driving, and-for example, take a 30 minute break encompassing a short $(<15$ minute) nap or coffee (about $150 \mathrm{mg}$ caffeine), which are very effective particularly if taken together. Exercise is of little use.
\end{abstract}

Conclusions-More education of employers and employees is needed about planning journeys, the dangers of driving while sleepy, and driving at vulnerable times of the day.

(Occup Environ Med 1999;56:289-294)

Keywords: sleepiness; vehicle accidents; circadian rhythm

\section{Background}

Sleep related vehicle accidents (SRVAs) are not only more common than is generally realised, but are more liable to result in death and serious injury owing to the relatively high speed of the vehicles on impact. ${ }^{12}$ Apart from the human misery caused, the financial cost of these accidents can be considerable, ${ }^{3}{ }^{4}$ especially if lorries are involved. Many SRVAs occur while the drivers are at work $^{4}{ }^{5}$-for example, driving company cars ${ }^{6}$ or lorries. ${ }^{7}$ Night work makes drivers particularly vulnerable - such as doctors on call, ${ }^{8}$ and those people driving home in the early morning after night shifts. ${ }^{9} 10$

In the United Kingdom, fatal road accidents involving lorries, per 100 million vehicle kilometres, is almost double that for cars (averaging $2.1 v 1.1$ over the past 5 years ${ }^{11}$ ). Many of these deaths are of car drivers and passengers after impact by the lorry. However, the extent to which these accidents are SRVAs is still not clear (see later). In the United States, the Department of Transportation now considers that there is a high likelihood that every lorry will be involved in at least one sleep related crash during the lifetime of the vehicle. ${ }^{12}$ Present European legislation (and United Kingdom law) prescribes that within any 6 day period a lorry driver can drive up to 56 hours (with prescribed breaks and rest periods, see later). If hours on duty are included (waiting in $\mathrm{cab}$, loading, and delivering goods) then the lorry driver can work up to 84 hours in a six day period. Most United Kingdom lorry drivers work up to these limits, and many go beyond this illegally.

The United Kingdom national database for road accidents, STATS 19 , does not normally record causal factors. Even when these (or contributory) factors are assigned, they are often assigned incorrectly. For example, many SRVAs, whether these involve cars, lorries, or other vehicles, are simply attributed to driver inattention. Often, accidents attributed to a tyre blow out are not always as they seem, as the tyre damage is a blow in caused by the accident, with the tyre impacting on the kerb or other solid object. This general situation regarding unreliable national statistics on SRVAs, is typical for most other western countries. ${ }^{913}$

In SRVAs the driver typically runs off the road or collides with another vehicle or object. A key sign is the absence of skid marks or other signs of hard braking beforehand (lorry tachographs can provide this evidence). It has to be established that for several seconds (about 7-10 s) immediately before the accident the 
driver could have seen clearly the point of run off or the object hit (implying prolonged inattention rather than momentary distraction). Other causes have to be eliminatedsuch as mechanical defect in the vehicle, bad weather, poor road conditions, speeding, driving too close, the driver having excess alcohol or a medical disorder, and, sometimes, even the possibility of the driver attempting suicide. Drivers who are able to respond after these accidents seldom acknowledge having fallen asleep (see below).

\section{Studies of accidents}

Long, undemanding, and monotonous driving, typified by motorways, facilitates sleepiness, ${ }^{14-16}$ as does any other tedious task. ${ }^{17} \mathrm{~A}$ recent, substantial United Kingdom survey by Maycock, ${ }^{6}$ covering 4600 respondents, found that $29 \%$ admitted to having felt close to falling asleep at the wheel in the previous year, and $17.9 \%$ had accidents during the previous 3 years. Of these, and for those accidents on motorways, 15\% were SRVAs. Maycock also showed that company car drivers had, as might be expected, a greater likelihood of having SRVAs by virtue to their greater exposure to driving, and driving long distances.

Few SRVAs occur on urban roads because the driving conditions are relatively stimulating, and usually there is much for the sleepy driver to see and do. By contrast, on non-urban roads, $\mathrm{we}^{2}$ have estimated from an analysis of all accidents in Devon and Cornwall over a 5 year period, and to which the police were summoned, that $16 \%$ were SRVAs. Although Maycock ${ }^{6}$ has given a lower estimate, at $9 \%$ of total vehicle accidents being related to sleep, this included accidents on urban roads, where the police were not present (minor shunts). Thus it is likely that these two estimates are reasonably consistent. The situation is worse for motorways, where $\mathrm{we}^{2}$ found that around $20 \%$ of accidents were probably SRVAs. Maycock ${ }^{6}$ reported this level to be somewhat lower, at $15 \%$.

In the United Kingdom there are clear time of day effects for SRVAs, ${ }^{26}$ with peaks around 0200-0600 and 1400-1600. This has been found for other countries, such as the United States, ${ }^{9}{ }^{18}$ Israel, ${ }^{1}$ Finland, ${ }^{19}$ and France. ${ }^{20}$ If the variations of traffic density over the day are taken into consideration, then the probability of SRVAs in the early morning is even greater. ${ }^{21}$ For example, at around 0600 drivers are over 20 times more likely to fall asleep at the wheel than at around $1000 .^{21}$ At about 1600 they are three times more likely to do so than at about 1000 or 1900 , the time when the circadian rhythm of sleepiness is least. Periods of the day vulnerable to SRVAs are distinct from the peak times for all road accidents in the United Kingdom, which occur during the commuting periods of around 0800-0900 and 1700-1800.

Sleepiness produced by prescribed drugs, alcohol, and other substances, is influenced by the circadian changes in sleepiness. Alcohol consumed early in the afternoon is about twice as potent in producing sleepiness and driving impairment as the same dose taken in the early evening. $^{22}$ In both situations, blood alcohol concentrations (BACs) were similar. Even a working lunch with relatively small amounts of alcohol, leading to BACs well within United Kingdom driving limits, can produce considerable driving impairment under motorway conditions. ${ }^{22}$ The business lunch involving moderate alcohol consumption, well within the legal driving limit, presents increased risk for motorway driving that afternoon.

$\mathrm{We}^{2}$ have found that drivers under 30 years old (usually men) are particularly prone to SRVAs in the early morning. Although this is at least partly due to them being the most prevalent group of road users at this time of day, they may also be at a greater risk, as there is increasing evidence that young adults undergoing sleep loss experience greater levels of sleepiness than they realise, or are prepared to recognise. ${ }^{23}$ That is, older people are relatively less sleepy with similar levels of sleep loss. However, with increasing age, the daily peak of SRVAs seems to shift to later in the day, and among those drivers aged 50-69 it is in the early afternoon. ${ }^{21}$ Of course, it is possible that these older drivers are not particularly at risk then, but are more likely to drive at these times. Unfortunately, there are no United Kingdom norms on road usage by age of the driver and time of day.

Much laboratory evidence, unrelated to SRVAs, shows overwhelmingly that the time of day when one undertakes a monotonous task is as important relative to sleepiness as is the duration of the task. ${ }^{17}{ }^{24}$ Nevertheless, the European Union regulations for lorry drivers' working hours allows them to drive 4.5 hours continuously without a break (4.0 hours for a bus or coach driver) irrespective of the time of day. If one includes the driver's non-driving duty hours then the period without a break can be extended considerably. To our knowledge there are no convincing data on which to base any premise that 4.5 hours is generally a safe duration of time for a lorry driver to drive, especially on monotonous roads. All the accidents related to early morning sleep (albeit few) that we reported ${ }^{2}$ involving lorry drivers, occurred within 2 hours of the start of the journey. Drivers of vans and taxis have no restrictions on their driving hours.

A recent Swedish occupational health study ${ }^{25}$ involving 6000 respondents, showed (by stepwise multiple regression) that involuntarily falling asleep at work was significantly related to the independent factors of: shiftwork (odds ratio (OR) 1.40), solitary work (OR 1.3), and disturbed sleep (OR 2.4). This study did not specifically target lorry drivers, but it strongly suggests that such a driver, driving alone at night (working long hours), having previously relied only on the sleeping facilities provided by the lorry's rear bunk, and with the vehicle parked near a noisy road or lorry park will, together, present a particularly hazardous combination. Interestingly, this study ${ }^{25}$ found that drinking coffee reduced the likelihood of falling asleep at work (OR 0.76), and is a topic that we will consider further (see later).

Increasingly, shiftworkers are changing over to a 12 hour shift system, with the night period 
usually starting at 1800 or 1900 . A recent, major study ${ }^{26}$ comparing 8 hour with 12 hour shift systems found that although there were few overall differences in alertness during work hours, the 12 hour participants were significantly more sleepy at the end of the shift, particularly at 0700 . The safety of these people is problematic when driving home, particularly if this involves monotonous driving for more than 20 minutes. $\mathrm{We}^{27}$ have shown that 20 minutes is the limit of safe driving under these conditions (see below). Insufficient research has been undertaken into this driving home aspect of night work.

\section{Clinical causes of driver sleepiness}

Driver sleepiness is usually not associated with sleep disorders, but is found typically in healthy people ${ }^{20}$ who had had insufficient sleep or were driving at their circadian nadir. When a pathological cause is present, this tends to be a sleep related breathing disorder, commonly sleep apnoea. Estimates of the increased risk that people with these breathing disorders have of having an SRVA, compared with age related normal subjects, vary from no difference ${ }^{28}$ to around twice as likely, ${ }^{729}$ and even up to four times greater. ${ }^{31}$ Although these drivers may be at a higher risk, they may compensate by reducing or otherwise modifying their driving habits. ${ }^{28}$ By contrast, it has been argued ${ }^{32}$ that driving impairments and accidents are underreported by these people. The obstructive variety of sleep apnoea tends to be associated with obesity, particularly a fat neck. ${ }^{30}$ In lorry drivers a positive correlation has been found between obesity or collar size and increased risk of SRVA. ${ }^{7}$ Medicolegal issues about accidents caused by these and other drivers with sleep disorders, are complex. ${ }^{33}$

\section{Driver forewarning of falling asleep}

Most drivers causing SRVAs usually deny having fallen asleep, and the evidence pointing to the accident being related to sleep has to come from other sources. There are possible reasons for this denial-such as fear of prosecution and loss of insurance indemnity. But it is more likely that the person genuinely had no recollection of actually having fallen asleep. Sleep laboratory studies show that people who fall asleep typically deny having been asleep if awoken within a minute or two. This was showed many years ago, ${ }^{34}$ and again more recently. ${ }^{35}$ Gastaut and Broughton ${ }^{34}$ reported that 2-4 minutes of sleep had to elapse before $>50 \%$ of people acknowledged that they were asleep. These investigators noted that, "subjective sleep onset appears to be a relatively lengthy period during which perception of state is blurred and uncertain". As a driver cannot remain asleep for more than a few seconds without having an accident, this may account for why such recollection is poor in drivers having had SRVAs.

However, this is no excuse for drivers falling asleep at the wheel. Although they may not acknowledge having fallen asleep, it is very likely that they were aware of the precursory feeling of sleepiness, even though they may also not remember this after the accident. In the only published study ${ }^{36}$ to monitor subjective sleepiness in healthy, sleepy drivers while they were driving, the authors noted that all their drivers were aware of their lowered arousal, and those who fell asleep had to fight sleep beforehand and in doing so knew the risk of falling asleep. Unfortunately, the study was extreme in that driving continued for many hours until the drivers fell asleep.

These findings, obtained from drivers while they were driving, contrast with two other related studies ${ }^{37}$ which asked their drivers to think back often weeks, months, and even years after a SRVA. These two studies were related, and both claimed that drivers who fall asleep at the wheel can have no foreknowledge of sleepiness beforehand, and that for them the sleep episode was a surprise. Such claims have influenced medicolegal arguments relating to driver culpability. However, analysis of both reports $^{37} 38$ shows that their conclusions are misguided and based on the same misleading questions incorporated into identical questionnaires. One question was the ambiguous and seemingly unanswerable, "While driving I become drowsy before I am aware of it", which does not differentiate between knowledge of earlier sleepiness and knowledge of having fallen asleep. The other question, "I have gone to sleep for short periods while driving without being aware that I am going to sleep", only inquires about having fallen asleep, not earlier sleepiness.

To our knowledge, there are few, if any other relevant reports, apart from our own recent study, ${ }^{39}$ which assessed the association between subjective sleepiness and driving impairment in sleepy drivers driving a full size, interactive car simulator, and under moderate conditions of sleepiness. We ${ }^{39}$ also examined the progress of sleepiness before falling asleep and the possibility that drivers who feel very sleepy misperceive or disassociate this from the perceived likelihood of actually falling asleep. Healthy young adult experienced drivers, who had had their sleep restricted to 5 hours the night before, drove for 2 hours in the afternoon. Lane drifting, typifying sleepy driving, was subdivided into minor incidents (one wheel out of lane) and major incidents (all wheels out of lane), where major incidents were indicative of actually falling asleep. A distinction was made between the subjective perceptions of sleepiness and the likelihood of falling asleep, with drivers reporting these separately. Increasing sleepiness was closely associated with rising driving incidents. Major incidents (potential accidents) were preceded by self awareness of increasing levels of sleepiness, starting about 40 minutes before the major incident. Typically, subjects had reached the stage of fighting sleep when these major incidents happened. Although the perceived likelihood of falling asleep was highly correlated with increasing sleepiness, some subjects failed to appreciate that extreme sleepiness is accompanied by a high likelihood of falling asleep. Nevertheless, it was not possible for our subjects to fall asleep at the wheel and have a major incident without 
experiencing a sustained period of increasing sleepiness, of which they were quite aware. Of course, in as much as these findings come from a laboratory simulation there is the problem of the extent to which these can be generalised to the real world. But given the danger and ethical problems confronting a real study, such laboratory investigations are all we can go on. Clearly, these findings strongly suggest that there is a need to educate at least some drivers that extreme sleepiness is very likely to lead to falling asleep and an accident.

\section{Can devices in vehicles help to alert the sleepy driver ?}

Many vehicle and other manufacturers are attempting to develop monitors of driver sleepiness in the vehicle, to alert the driver. However, as Lisper et $a l^{36}$ aptly remarked, "what is the use of alerting a driver already aware of the fact that $\mathrm{s} / \mathrm{he}$ is close to sleep but who unwittingly still continues to drive ?" In the United Kingdom there is increasing concern that such devices (of unproved reliability) may encourage sleepy drivers simply to take further risks and continue to drive, thinking that the device will alert them when the situation becomes particularly dangerous.

Why do sleepy drivers persevere with their driving, beyond the point when they are fighting sleepiness, and should stop driving ? Do they not realise the risks involved? Sleepiness might cloud a person's judgement about the extent of the driving impairment, although recent laboratory findings unrelated to driving ${ }^{40}$ show that sleepy subjects are usually aware of the extent of their deteriorating performance. It is possible that sleepiness affects mood, making drivers more optimistic, less cautious, and even more reckless with their driving. There is evidence from more extreme sleep loss studies that this can happen, ${ }^{41}{ }^{42}$ but there is no such research relevant to sleepy driving.

\section{Symptoms of falling asleep at the wheel}

The potential danger of driving motivates most sleepy drivers into putting much effort into remaining awake. As a result the process of falling asleep at the wheel is not the same as when one lies down in bed, expecting to sleep, and falling sharply into obvious sleep. The sleepy driver fighting sleep exhibits different durations and sequences of the physiological events that precede the onset of sleep. ${ }^{43}$ Hence, the various physiological measures that can be used to measure falling asleep can show poor associations with each other even under the best laboratory conditions. ${ }^{44}$ This is a problem that besets the development of physiological monitoring devices for detecting driver sleepiness. Although the classic signs of sleepiness are obvious, those of starting to go to sleep are not simple matters to detect in the driver, as the electroencephalogram often reflects a condition of neither being awake nor asleep, with the driver being in a protracted state of quasisleep. Even the closing of the eyes, which occurs during the normal process of falling asleep, can be delayed to the point that some of our subjects ${ }^{43}$ could be described as being asleep with their eyes open. Such a phenomenon was first noted 70 years ago by Miles, ${ }^{45}$ who said, "a motorist or anyone may actually be asleep, even if the eyes are seen to be open". This finding throws further doubt on the effectiveness of any device for detecting driver sleepiness that relies on eye closure. Eye blink rates have been claimed to be a good index of sleepiness, ${ }^{46}$ but we ${ }^{43}$ have found it to be unreliable, as blinking in the driver is also affected by the outside road lighting, oncoming headlights, and the air temperature and state of the ventilation system in the vehicle.

Typically, a car being driven by a driver falling asleep either runs into a vehicle in front, or weaves or drifts off the carriageway. Variability in speed is not so reliable an index ${ }^{47}$ and depends on the force required to depress the accelerator. Falling asleep is accompanied by reduced muscle tone throughout much of the body-for example, head rolling-and foot pressure on the accelerator pedal will relax. However, the outcome with respect to vehicle speed will depend on how much the accelerator pedal return spring counteracts foot pressure. The scientific literature is unclear about the more subtle changes to steering that may occur during sleepy driving. One recent account ${ }^{48}$ claimed that steering wheel reversals are a good indicator of sleepiness, with both the number and amplitude of these increasing with sleepiness. However, the extent of such changes depends on experience and driving skills, as good drivers maintain a more constant number of corrections than do poorer drivers. ${ }^{48}$

The response time in applying the brakes in an emergency is commonly thought to be impaired by sleepiness. But this may not always be the case, as laboratory studies indicate that the driver will either respond almost normally or not at all (hence a collision). That is, response time becomes disrupted rather than shows a gradual decline. ${ }^{47}$ Measurement of a driver's reaction time to pushing a button on the steering wheel, in response to a randomly generated sound from within the car, has been studied as a potential device for monitoring driver sleepiness. However, a recent, unpublished comprehensive review ${ }^{49}$ of reaction time as an indicator of driver sleepiness, concluded that many aspects of this area require further investigation, and it cannot be said with any confidence that a reaction time fatigue monitor could be made both effective and reliable. Other investigators ${ }^{50}$ advocate caution about such methods, as they could be used by the sleepy driver as a form of entertainment to relieve the monotony and distract him or her from the driving. In summary, the most valid and reliable method for detecting driver sleepiness lies with the drivers' own personal knowledge of their sleepiness.

\section{Practical counter measures}

The best advice to a driver falling asleep at the wheel is to stop driving as soon as possible. Although motoring organisations advocate various methods in the vehicle to counteract sleepiness, such as cold air to the face (opening 
the window) or turning up the car radio or tape player, there is no scientific evidence to endorse this. ${ }^{51} \mathrm{We}^{51}$ have shown that both methods provide only temporary benefit, being only partially effective for a short period (about 15 minutes). That is, these techniques should not be used to prolong driving, but may provide enough time for the driver to locate and stop at a suitable place to park and rest. In some cases, listening to the radio, or rather attempting to listen to the radio, can distract sleepy drivers from being so aware of their sleepiness and impaired driving. ${ }^{51}$

"Take a break" is clearly good advice as it necessitates stopping driving. The best counter measure to sleepiness is to sleep, or at least to take a nap. In a comprehensive review on the minimal sleep to maintain performance, Naitoh $^{52}$ concluded that 4 minutes was the minimum. Naps beyond 20 minutes can be counterproductive as they develop into a full sleep, leading to difficulty in arousing and a postsleep inertia (thick headedness, heavy limbs, difficulty in getting going ${ }^{53}$ ). Fifteen minute naps taken every 6 hours during a 35 hour period of no sleep have been shown to be very effective in maintaining performance. ${ }^{52}$ Recently, Gillberg et $a \vec{l}^{4}$ reported that a 20 minute nap taken in the morning after a sleep restricted to 4 hours the previous night reversed behavioural deficits later that morning, and again that afternoon.

Most car and lorry seats are well designed for napping, perhaps too much so if one is actually driving. In fact, modern vehicle comfort and ergonomic layout of the controls, as well as sound reduction, are so good that sleepiness at the wheel might, unwittingly, be enhanced by such good features.

The next most feasible method for alleviating sleepiness is a pharmacological stimulant, with the most acceptable being caffeine (as in coffee). It has few adverse side effects at doses that can be taken in reasonable amounts of coffee-two cups give around 150 $\mathrm{mg},{ }^{55}$-although, cups of coffee do vary considerably in caffeine content. Coffee also contains small amounts of other stimulantsfor example, theophylline. Laboratory work outside the field of driving has shown that caffeine in relatively low doses (100-200 mg) significantly improves alertness in sleepy subjects. $^{56-58}$

Little by way of systematic research has been undertaken on the effects of caffeine or napping on driving. $\mathrm{We}^{43}$ have compared: a nap of $<15$ minutes, $150 \mathrm{mg}$ caffeine, and a caffeine placebo, each given randomly (double blind) across test sessions, to sleepy drivers during a 30 minute rest period between two, 1 hour afternoon drives in a car simulator. Caffeine taken in this manner takes about 30 minutes to become effective. To enhance afternoon sleepiness, subjects were sleep restricted to 5 hours the night before. Both caffeine and the nap significantly reduced major and minor driving incidents (lane drifting, as already described), subjective sleepiness, and electroencephalographic signs of drowsiness. The effects with caffeine lasted for the hour of driving and were consistent across all subjects, whereas for the nap, less so, as some subjects had difficulty napping. However, even 15 minutes of nonsleep dozing was beneficial. Taking a 30 minute break, alone (placebo) was only effective for about 15 minutes after restarting the driving. In another study ${ }^{59}$ of a longer duration (2 hours) drive, we have shown that the combination of caffeine with a nap, whereby $150 \mathrm{mg}$ caffeine was taken immediately before a nap or doze of up to 15 minutes (both within a 30 minute break) had a powerful and enduring effect in suppressing sleepiness and driving incidentsmore potent than either method alone. We do not advocate that drivers rely on higher (pharmacological) doses of caffeine, as this implies that they are too sleepy, and hence, should not be driving at all. However, in an emergency, rather than caffeine in high doses, a schedule of short naps would be more beneficial. ${ }^{52-54}$

As already noted, SRVAs have a high incidence in the early morning, especially in younger drivers, and particularly in night shift workers returning home. In a further study ${ }^{27}$ in our laboratory, young drivers who had a night of no or restricted ( 5 hours) sleep, drove for 2 hours (0600-0800) continuously after ingesting (at 0530) $200 \mathrm{mg}$ caffeine (about 3 cups of coffee) or placebo, in a counterbalanced double blind design. Caffeine was effective in reducing sleepiness and driving incidents for only up to 30 minutes in those drivers who had been up all night. For those who had 5 hours sleep, caffeine significantly reduced incidents and subjective sleepiness throughout the 2 hour drive and was of considerable benefit.

Sleepy drivers are often recommended to go for a walk or take some exercise during a break from driving, but again, there is no strong evidence in support of this. We ${ }^{60}$ have examined the effects of 10 minute bouts of light, moderate, and heavy exercise in sleepy subjects. Only the heavy exercise resulted in any marked and enduring improvement in alertness (lasting for up to 30 minutes). Several subjects reported that the moderate and light exercise seemed to make them more alert; but this effect only lasted for about 10 minutes. Unfortunately, the heavy exercise regime is too great for most people to be of any practical benefit.

\section{Conclusions}

Vehicular accidents related to sleep can be reduced through a greater awareness by drivers and employers of the danger of driving while sleepy, and that such driving behaviour is unacceptable, particularly to other road users. Work and other time schedules should be planned so as to minimise exposure to prolonged driving under monotonous conditions during the more vulnerable times of the day and night. The best and most accurate information drivers have at their disposal about their state of sleepiness comes from their own self awareness of sleepiness. What many drivers fail to appreciate is that sleepiness portends sleep, which can come on more rapidly than they realise, especially if the driver has reached the more profound stage of fighting off sleep. This involves acts such as opening the vehicle's 
window, turning up the radio, the driver often moving around in the driving seat-actions whereby the driver must fully realise that he or she is very sleepy. At which point the driver should stop driving as soon as possible and take a break for at least 30 minutes, drink caffeinated coffee, and if feasible, take a brief nap. In summary, we advocate heightened public awareness, greater employer responsibility, and better education of drivers about SRVAs, which cause numerous road casualties each year.

This research is supported by the United Kingdom Department of the Environment, Transport, and the Regions.

1 Zomer J, Lavie P. Sleep-related automobile accidentswhen and who? In: JA Horne, ed. Sleep '90. Bochum: Pontenagel Press, 1990.

2 Horne JA, Reyner LA. Sleep related vehicle accidents. BMF

3 Mitler MM, Carskadon MA, Czeisler CA, et al. Catastrophes, sleep and public policy: consensus report. Sleep 1988 11:100-9.

4 Leger D. The cost of sleep-related accidents: a report for the National Commission on Sleep Disorders Research. Sleep 1988;17:84-93.

5 McCartt AT, Ribner SA, Pack AI, et al. The scope and nature of the drowsy driving problem in New York State. Accid Anal Prev 1996;28:511-17.

6 Maycock G. Sleepiness and driving: the experience of UK car drivers. F Sleep Res 1996;5:229-37.

7 Maycock G. Sleepiness and driving: the experience of heavy goods vehicle drivers in the UK. F Sleep Res 1997;6:238-44.

8 Marcus CL, Loughlin GM. Effect of sleep deprivation on driving safety in housestaff. Sleep 1996;19:763-6.

9 Pack AI, Pack AM, Cucchiara A, et al. Characteristics of crashes attributed to the driver having fallen asleep. Accid Anal Prev 1995;27:769-75.

10 Lyznicki JM, Doege TC, Davis RM, et al. Sleepiness, driving, and motor vehicle crashes. $7 A M A$ 1998;279:19081913.

11 Department of Environment, Transport, and the Regions. Accidents Great Britain 1997-the casualty report. London: Accidents Great Britain 1997-the cas

12 Knipling RR, Wang J-S. Crashes and fatalaties related to driver drowsiness/fatigue. Washington, DC, Office of Crash Avoidance Research, US Department of Transportation, Research note, 1994

13 Akerstedt T, Czeisler CA, Dinges D, et al. Accidents and sleepiness: a consensus statement. F Sleep Res 1994;4:195.

14 Brown I. Driver fatigue. Hum Factors 1994;36:2398-414.

5 Kjellberg A. Sleep deprivation and some aspects of performance III. Waking and Sleeping 1972;1:49-153.

16 Finkelman JM. A large database study of the factors associated with work-induced fatigue. Hum Factors 1994;36:23243.

17 Mavjee V, Horne JA. Boredom effects on sleepiness/ alertness in the early afternoon vs early evening and interactions with warm ambient temperature. Br f Psychol 1994; 85:317-33.

18 Langlois PH, Smolensky MH, Hsi Bp, et al. Temporal patterns of reported single-vehicle car and truck accident Chromobiol Int 1990;2:131 46.

19 Summala H, Mikkola T. Fatal accidents among car and truck drivers: effects of fatigue, age, and alcohol consumption. Hum Factors 1994;36:315-26.

20 Philip P, Ghorayeb I, Stoohs R, et al. Determinants of sleepiness in automobile drivers. F Psychosom Res 1996;41 279-88.

21 Horne JA, Reyner LA. Driver sleepiness. F Sleep Res 1995;4(suppl 2):23-9.

22 Horne JA, Baumber CJ. Time of day effects of alcohol intake on simulated driving performance in women. Ergonomics 1991;11:1377-83.

23 Brendel DH, Reynolds CF, Jennings JR, et al. Sleep stage physiology, mood and vigilance responses to total sleep deprivation in healthy 80 year olds and 20 year olds. deprivation in healthy 80 8 year

24 Monk T, ed. Sleep, sleepiness and performance. Chichester: Wiley, 1991.

25 Akerstedt T, Knutsson A, Westerholm P, et al. Work organisation and involuntary sleep at work. I Sleep Res

26 Tucker P, Barton J, Folkard S. Comparison of eight and 12 hour shifts: impacts on health, wellbeing, and alertness during the shift. Occup Environ Med 1996;53:767-72.

27 Reyner LA, Horne JA. Caffeine $(200 \mathrm{mg}$ ) as a countermeasure to early morning driver sleepiness after nil or restricted sleep. F Sleep Res 1998;7(suppl 2):223.
28 Hanning CD, Welsh $M$. Sleepiness, snoring and driving habits. 7 Sleep Res 1996:5:51-4.

29 Aldrich MS. Automobile accidents in patients with sleep disorders. Sleep 1989;12:487-94.

30 Davies RJ, Ali NJ, Stradling JR. Neck circumference and other clinical features in the diagnosis of the obstructive sleep apnoea syndrome. Thorax 1992;47:101-5.

31 Young T, Blustein J, Finn L, et al. Sleep-disordered breathing and motor vehicle accidents in a population-based sample of employed adults. Sleep 1997;20:608-13.

32 Engleman HM, Hirst WSJ, Douglas NJ. Under reporting of sleepiness and driving impairment in patients with sleep apnoea/hyponea syndrome. F Sleep Res 1997;6:272-5.

33 O'Keefe R. Sleep disorders and the Law of Torts. Fournal of Law and Medicine 1996;3:283-95.

34 Gastaut H. Broughton R. A clinical and polygraphic study of episodic phenomena during sleep. In: J Wortis, ed. Recent advances in biological psychology. New York: Plenum Press, 1965;7:197-223.

35 Bonnet MH, Moore SE. The threshold of sleep: perception of sleep as a function of time asleep and auditory threshold. Sleep 1982;5:267-7

36 Lisper H-O, Laurell H, van Loon J. Relation between time to falling asleep behind the wheel on a closed track and changes in subsidiary reaction time during prolonged driving on a motorway. Ergonomics 1986;29:445-53.

37 Tilley DH, Erwin CW, Gianturco DT. Drowsiness and driving: a preliminary report of a population survey. Proceedings of the International Automotive Engineering Congress, fan 8-12. Detroit, MI: 1973:10-18.

38 Jones TO, Kelly AH, Johnson DR. Half a century and a billion kilometres safely. Transactions of the Society of Automotive Engineering, 1979;87:2271-302.

39 Reyner LA, Horne JA. Falling asleep whilst driving: are drivers aware of prior sleepiness? Int $\mathcal{F}$ Legal Med 1998;111: $120-3$

40 Baranski JV, Pigeau RA, Angus RG. On the ability to self-monitor cognitive performance during sleep deprivation: a calibration study. Fournal of Sleep Research 994;3:36-4

41 Horne JA. Why we sleep. Oxford: Oxford University Press, 1988

42 Horne JA. Human sleep, sleep loss and behaviour, implications for the prefrontal cortex and psychiatric disorder. $\mathrm{Br}$ f Psychiatry 1993;162:413-19.

43 Horne JA, Reyner LA. Counteracting driver sleepiness: effects of napping, caffeine and placebo. Psychophysiology 1996;33:306-9.

44 Ogilvie RD, Wilkinson RT, Alison S. The detection of sleep onset: behavioural, physiological and subjective convergence. Sleep 1989;12:458-74.

45 Miles W. Sleeping with the eyes open. Sci Am 1929;140: $489-92$.

46 Stern JA, Boyer D, Schroeder D. Blink rate: a possible measure of fatigue. Hum Factors 1994;36:285-97.

47 Riemersma JBJ, Sanders AF, Wildervanck C, et al. Performance decrement during prolonged night driving. In: Mackie, ed. Vigilance. New York: Plenum Press, 1977.

8 Khardi S, Vallet M. Drivers vigilance, analysis of differences in vigilance states assessments by physiological and mechanical indicators. Conference Proceedings: Telematics for Transport. Paris, 1994;1991-8.

49 Maycock G. Reaction time as an indicator of driver sleepiness. Crowthorne, UK: Transport Research Laboratory, 1998. (Unpublished project report PR/SE/390/98.)

50 Mackie RR, Wylie CD. Countermeasures to loss of alertness in truck drivers theoretical and practical considerations. In: $M$ Vallet, ed. Le Maintien de la Vigilance dans les Transports. Caen: Paradigme, 1991:113-41.

51 Reyner LA, Horne JA. Evaluation of "in car" countermeasures to driver sleepiness: cold air and radio. Sleep 1998;21: 6-50.

52 Naitoh P. Minimal sleep to maintain performance: the search for the sleep quantum in sustained operations. In: C Stampi, ed. Why we nap. Boston: Birkhauser, 1992:198219.

53 Dinges D. Adult napping and its effects on the ability to unction. In: C Stampi, ed. Why we nap. Boston: Birkhauser, 1992:118-34.

54 Gillberg M, Kecklund G, Axelsson J, et al. Counteracting sleepiness with a short nap. Fournal of Sleep Research 1994,3 (suppl 1):90

55 Fox S. Coffee, caffeine and health. Members reference book. London: Royal College of General Practitioners, 1993.

56 Lumley M, Roehrs T, Asker D, et al. Ethanol and caffeine effects on daytime sleepiness alertness. Sleep 1987;10:306-

57 Griffiths RR, Evans SM, Heishman SJ, et al. Low-dose caffeine discrimination in humans. F Pharmacol Exp Ther 1990;252:970-8.

58 Lorist MM, Snell J, Kok A, et al. Influence of caffeine on selective attention in well-rested and fatigued subjects. Psychophysiology 1994;31:525-34.

59 Reyner LA, Horne JA. Suppression of sleepiness in drivers: combination of caffeine with a short nap. Psychophysiology 1997;34:721-5.

60 Horne JA, Foster SC. Can exercise overcome sleepiness? Sleep Res 1995;24:437. 